\title{
MANA MOTUHAKE O NGĀTI POROU: DECOLONISING HEALTH LITERACY
}

\author{
Teah Carlson ${ }^{1}$
}

\begin{abstract}
This paper explores decolonising health literacy by reclaiming historical practices shared by Māori to develop a kaupapa Māori health literacy evaluation framework. The work is based on a research innovation within a Primary Health Organisation - Ngäti Porou Hauora - that defines health literacy within the context of the community. This research promotes reclamation of health literacy as a space for Māori to be ourselves; a space that is negotiated, adaptive, and shaped by people, whānau (family group) and communities. The framework attempts to reflect participants' voices, perceptions, understandings and experiences. Its design was informed by a kaupapa Māori praxis, and aspires to co-ownership, mutually beneficial outcomes and shared power through prioritising participants' voices to shape and develop the criteria for determining the goals and action areas related to health literacy. The framework includes overall goals and action areas for practicing effective health literacy at individual, whānau, health professional, intervention/programme, and organisational levels. This paper is an example of how Māori can promote and practice health literacy in the context of our histories, honouring a pathway of transformation through decolonising methods.
\end{abstract}

Keywords: health literacy; evaluation practices; Indigenous; kaupapa Māori evaluation; decolonisation.

\section{INTRODUCTION}

In Aotearoa New Zealand, the effects of colonisation on Māori health have resounded through the Māori world in deep and devastating ways ( Ajwani et al. 2003; Robson and Harris 2007) so the need for decolonisation toward Māori sovereignty is a powerful counter narrative. Through decolonisation, we (Māori) attempt to unravel what is distinctly ours and what is theirs, while 
what remains unclaimed is a matter for debate (Smith 2015). How do we create pathways to health that are free from colonialism, and grounded in mana motuhake (self-determination)? To what extent might this be possible? We begin with what makes us Māori: our place - whānau, hapū (sub-nation) and iwi (nation); our space - relationships, connections to each other, our environment and our spiritual cosmos; and our time - our lived history, including resisting colonisation and a constant striving for action and change.

Through intensive research, mostly 'on' Māori, Western researchers have (re) discovered, fragmented, appropriated, and objectified Māori knowledge: 'They came, they saw, they named, they claimed' (Smith 1999a, 80). But improved outcomes have not been forthcoming (Bishop 1999; Irwin 1994; Smith 1999b). Consequently, it is not surprising that many Mãori question the value of health research and its agenda. Contemporary research with Indigenous Peoples requires approaches and methods that catalyse constructive change and are relevant to the lives of the people who participate. Decolonising research must address issues of power, especially the power to identify issues, determine the research and evaluation agenda, and prescribe methods/methodologies (Bishop 2005; Durie 2004; Smith 1999a).

In Aotearoa, kaupapa Māori research advances the decolonisation agenda by privileging Indigenous voices and epistemologies in collaborative or collective research processes. Kaupapa Māori research utilises a wide range of methods, including evaluation (Pihama, Cram, and Walker 2002). Kaupapa Māori evaluation can be described as a process of exploration, innovation, and explanation using Māori forms of enquiry and accountability measures, and criteria (Cram and Lenihan 2000; Kawakami et al. 2007).

This paper explores the potential of kaupapa Māori evaluation from the standpoint of a local, iwi-based health organisation in my home territory of Ngāti Porou. I focus on creating an evaluation framework for a health literacy initiative, underpinned by a powerful commitment to mana motuhake. I begin by contextualising the initiative to the region (rohe) and people among whom it arose and was implemented. Next, I explore impacts of colonisation on health services and health literacy in particular, before introducing kaupapa Māori health literacy. Along with an interrogation of conventional evaluation approaches. I discuss the use of kaupapa Màori evaluation practices in the development of a location-specific Health Literacy Evaluation Framework. The framework is described as an exemplar of a kaupapa Māori evaluation of a collaborative approach based on mana motuhake. 
For over a thousand years, Māori have adapted and innovated in response to our environment. The natural environment provided spiritual, theoretical, and ethical foundations that 'gave rise to codes for living that would ensure the well-being for future generations' (Durie 2013, 183). In the years after settling Aotearoa, Māori were healthy, robust, agile and mentally active. We lived in tune with nature and, when mature, were at the peak of fitness, as the weak would not survive the hardships of primal life (Pomare 1909).

Some of the earliest European observations of life in Aotearoa, described an Indigenous People with a strong health philosophy and a health system based on social and cultural concepts practiced successfully within the community (Beaglehole 1955; Salmond 1991). Māori were described as well-built, fit, and remarkably healthy (Hanham 2003; Nicholas and Watkins 1838; Watkins 1838) with a rapid healing ability, indicating a healthy immune system (Hanham 2003). Health and wellbeing were understood as conditions of moral and spiritual wholeness. 'Spiritual' practice aligned every action to the workings of the natural world on which Māori depended (Hanham 2003). Good health, 'ora', was important and appreciated and 'hauora' (health and wellbeing) was conceptualised as a holistic state of wellbeing and abundance (Hanham 2003).

However, colonisation brought new diseases, technologies, and novel foods, as well as introducing racism, oppressive religion, education, discriminatory governance, and exploitative economic practices (Salmond 2017). From the 1820s, Māori communities suffered intertribal conflict, military invasion, land alienation, resource destruction, dehumanisation, and deculturation (Durie 2013). Customary traditions were tested by new social and material practices which were inherently unsustainable and caused extensive ecological destruction (Cram 2009). Māori populations declined, damaging the effectiveness of tribal organisation and often threatening the very existence of smaller tribal groups.

\section{A NGĀTI POROU PERSPECTIVE ON HOLISTIC HEALTH}

These impacts of colonisation were felt by Ngāti Porou, and the effects of colonial force still reverberate in contemporary Aotearoa. Honouring Mana Motuhake o Ngāti Porou begins with pūrākau (ancestral history). The people of Ngāti Porou are descendants of Māui-Tikitiki-a-Taranga. When Māui fished up Te Ika-a-Māui (North Island), two rocks appeared. He named these two rocks Hikurangi and Aorangi after two maunga (mountains) which stood in his homeland of Hawaikii. It was Hikurangi that raised his waka (canoe), 
Nukutaimemeha, out of the water and it rests there to this day. Ngati Porou boundaries spans from Toka-a-Taiau to Pōtikirua, in the Te Tai Rawhiti (Gisborne) rohe of Te Ika-a-Māui.

The communities engaged with my research are located in the area north of the Waiapu River, known as Rangitukia. Whakapapa links them to Ngāti Porou ki Potikirua ki Whangaikena, Whangaikena ki Waiapu, Pohautea ki Te Onepoto, and Te Onepoto ki Rahuimanuka. Expressions of mana motuhake acknowledge the interconnected relationship and embodiment of people and land. The name 'Rangitukia' means to break through to heaven, acknowledging terrestrial space. If you journey up the awa (river) to Tikitiki, you arrive in the area known as Tikitiki-o-rangi, another form of heaven - the telestial space. You then make your way to Hikurangi, the most prominent maunga on the East coast. 'Hikurangi' is the celestial heaven. The names of these places acknowledge the creator for giving us these lands. This is mana whenua (power from the land). To acknowledge land is to acknowledge spirit intertwined and inseparable.

Descriptions of life in the 1800 and early 1900 s in the Rangitukia and neighbouring Matakaoa regions describe lands that were thick in vegetation and divided by natural formations, awa, and maunga (Mahuika 2010).'The land back then was anybody's and everybody's. There weren't any exclusive boundaries between the families [...] there was a tremendous community spirit' (Karaka $2000,3)$. Communities were small, and everyone had a role and work to do. The ngahere (bush), moana (sea), awa, pūkaki (streams) and wairepo (swamps) were places of resource, sustenance and rongoā (medicines). Whānau (families) knew what could be consumed, what was poisonous, and what healed. Whānau knew the lands well, walking them every day to hunt for kai (food) and gather supplies.

For Ngāti Porou at this time, the health and wellbeing of the people were based on common sense and an intimate connection with the environment. Knowledge and everyday living were guided by tikanga (customary systems). The Waiapu river was (and is) their source of life, providing kai and spiritual sustenance. The health and wellbeing of the river is intimately connected to the people. When the river flooded, it was a sign that tapu (sacred state/condition) had been breached and atua (gods) were offended (Karaka 2000). When the waters were clear and flowing, life was in balance. The wellbeing of the people was based on a value system that was shared and understood by all, as captured by this Ngāti Porou whakataukī. 
Tautoko tetehi ki tetehi Awhina tetehi ki tetehi Aroha tetehi ki tetehi
To support one another

To help one another

To show love for one another

THE INTRODUCTION OF COLONIAL HEALTH SERVICES

In 1885, the government established the Cook and Waiapu Hospital Boards to manage the provision of hospital services in the East Coast rohe. In 1903, a small one-bedroom hospital was opened to serve almost the entire rohe. By 1900, the people of Ngāti Porou were suffering heavily from infectious diseases and other forms of illness. Typhoid and tuberculosis (TB) had hit the people at epidemic levels, and isolation huts became a common sight in communities. It is an utter disgrace what has happened to our people. Tauiwi (non-Māori) brought in diseases that killed off whole families, like typhoid, T.B., and influenza' (Tangaere 1999, 30). The very limited level of government help meant that many people relied on tohunga (expert healers). However, in 1907 the Tohunga Suppression Act was passed, outlawing Māori customary medical practices (Tangaere 1999). In 1918, an influenza pandemic struck Aotearoa, killing over 8,00o people in two months. Two thousand Māori died, a fatality rate over seven times that for Pākehā (Lange 1999).

The significant disparities in health between Māori (including Ngāti Porou) and Tauiwi have persisted since the 1920 (Robson and Harris 2007). In 1988, the Director General of Health characterised the development and implementation of government health policy and national health services as mono-cultural (Mahuika 2010). For example, until the 1970s, there was very limited Ngāti Porou representation on the Cook and Waiapu Hospital Boards. In response, Māori communities have been establishing their own health providers.

Ngāti Porou Hauora was initially established in 1995 as an incorporated society to provide integrated health services for all people residing within the iwi boundaries. At that time the rohe faced many issues, including poor health outcomes, limited access to services and low rates of employment. There was a yearning for an innovative, locally relevant service that reflected Mana Motuhake o Ngāti Porou. Ngāti Porou Hauora is currently the main provider of health services in the rohe, operating seven community health centres and a small rural hospital, offering various public and clinical health services at low to no cost for enrolled patients. 
Given the emergence of kaupapa Māori health providers, consideration of kaupapa Mãori health literacy seems the next logical step. The word literate is from the Latin literatus/litteratus - one who knows the letters, which later came to mean educated (Harper 2012). In Western epistemology, being educated equates to being schooled, well read, and knowledgeable. The term health literacy first appeared in a 1974 paper calling for minimal health education standards to be implemented in United States of America schools (Mancuso 2009). Since then, the concept has evolved, with numerous studies examining ways to measure 'health literacy', and describing problems related to low levels of health literacy (Schulz and Nakamoto 2013). The World Health Organisation describes health literacy as 'the degree to which people are able to access, understand, appraise and communicate information to engage with the demands of different health contexts in order to promote and maintain good health across the life-course' (Kanj and Mitic 2009, 4). Because of their supposed impact on individual health and healthcare costs, most examinations of health literacy have focused on functional aspects, which include basic literacy and numeracy. More recently, the concept of health literacy has expanded to encompass communicative/ interactive literacy and critical literacy (Nutbeam 2009). However, social and cultural considerations are still rarely discussed in the literature (Carlson et al. 2016). This marks an important opportunity for kaupapa Māori research to contribute towards decolonising health literacy, which although evolving from its Western clinical roots may benefit from transformations driven by Indigenous conceptualisations.

The growing acknowledgement of its multi-layered nature advanced the notion of health literacy as a social practice, positioning health literacy as a health system issue rather than as an issue of individual skill deficits. Health literacy, when understood as embedded in social and cultural practices (Rudd 2012; Rudd, McCray, and Nutbeam 2012; Papen 2009) requires an examination of context and consideration of patient agency and participation. Papen (2009) stressed critical analysis of information, social determinants of health, and engagement in collective action. Ross el al. (2009) suggested that strategies to improve health literacy must include multi-level approaches that practice collaborative, communitarian partnerships among people. Collective practice and relationship are fundamental concepts in the theorising of kaupapa Māori research and can be fruitfully extended to thinking about health literacy.

A systematic review by Sørensen et al. (2012) provided an overview of existing health literacy definitions and conceptual models and after a thorough em- 
pirical review of the dimensions of the domain, proposed a model integrating medical and public health views. The naturalisation of collective population framings arising from this model aligns with kaupapa Māori approaches. Their integrated model of health literacy indicates that, as a concept, health literacy is oriented to its functions within a system, so that as an intervention practice, its interests and concerns are also intra-systemic, rather than a critical analysis of the underpinning values and principles it promotes. This evolution represents a profound ideological, theoretical and practical problem for Indigenous People since it submerges and marginalises longstanding health practices, as well as concerns with social injustice and objectives around self-determination. In this sense, in this country and similar settings, the system so surfaced could be framed as 'un-reconstructed colonialism. In the absence of an overtly decolonising imperative, Mãori communities will question the assumptions, agendas and values that health literacy approaches and interventions serve and how they address the aspirations of the people (Damschroder et al. 2009).

\section{EVALUATING HEALTH LITERACY}

Health literacy is multidimensional, encompassing systematic and environmental demands and complexities as well as individual skills and attributes, which are influenced by contextual, social and cultural factors (Pleasant et al. 2016). Elsewhere, I have argued that health literacy researchers must analyse literacy as a set of practices entrenched in broader social accounts and cultural activity that reflect issues of equity, equality and self-determination (Carlson et al. 2016). These practices are crucial elements of kaupapa Māori research in this domain (and others). Accordingly, I propose that the effectiveness of health literacy practices and processes needs to be evaluated and redefined by the people that are affected by it - in this case, Māori whānau, hapū and iwi.

Because the use of the word 'literacy' typically privileges Western ways of knowing, literacy has been described as a tool of privilege and power in the communication and practice of the West (Papen 2006). Health literacy has similarly been described as legitimising colonial power, its worldview, principles, and values (Papen 2009; Peerson and Saunders 2009). However, history presents an important twist. Until the 186os, there were more Māori literate in te reo Māori than British colonists literate in English. These relative levels of literacy were only changed by civil war and the emergence of discriminatory policies, such as the Native Schools Act of 1867 . Drawing on traditions of Māori health philosophies, and a re-imagined understanding of 'literacy', I propose 'rewriting and rerighting' (Smith 1999a, 28) the historical account and practices of health literacy as a practice with a distinct Māori history. 
Western practices of evaluation focus on the systematic determination of the quality, value, or significance of something (Social Policy Research and Evaluation Unit [Superu] 2017). Māori communities have often endured evaluations that are not 'culturally and historically meaningful' (Kawakami et al. 2007, 330). However, I wish to reclaim evaluation as a helpful tool and process for monitoring and assessing the effects of colonial force on Māori society and health and wellbeing in the rohe, and for building a pathway of restoration, healing, and autonomy. The critical question for evaluation is: 'Who determines what is of value to our people?'

Within te ao Māori, something that is 'valued' is understood to be worthy or highly regarded, based on its connectedness to te tai ao (environment), pūmotu (elements), whānau, tipuna (ancestors) and te reo Māori (Māori language) (Kawakami et al. 2007). In accordance with our deep connection to the spiritual power inherent in land (and all things animate and inanimate that inhere in it), whakapapa and whānau, 'value' is based on principles and standards that determine the collective good (Durie 2013). Whānau, hapū and iwi may determine 'value' within their context, including those relationships in a specific time and place. Within the Māori worldview, the meaning of an evaluation is measured in terms of its practical and respectful impact on the lives of the participants and communities of particular locations (Mead 2003). Evaluations must be ethical, action-oriented, restorative, transformative, decolonising participatory and located. Processes must honour collective engagement approaches, and create pathways towards self-determination and cultural autonomy (Denzin and Lincoln 2008). Determining what we value is vitally important to the evaluation process because values determine the criteria for assessing the effectiveness or success of approaches and practices. The present research provides an insight into the 'value' we place on health literacy.

\section{PRACTICE IN THE CONTEXT OF HISTORY}

The term 'evaluation' in te reo Māori has been translated as 'aromātai'. 'Aro' means to take interest, to face towards, and 'matai' means to gaze intently and longingly. Contained within Māori histories are descriptions of processes and metaphors that relate to evaluative processes and theories, including collective advancement, problem-solving and decision making (Walker, Eketone, and Gibbs 2006). Empirical observation, analysis, problem solving, and progression have been part of our histories - from Tāne Mahuta who sought to bring the first human form into the world as Hineahuone, to Maui who restrained the sun, fished up land, brought fire into the world and searched for immortality. These processes of gaining knowledge embody the many environmental, eco- 
nomic, and social practices adopted and adapted by tangata whenua (people of the land). These pūrākau (ancient legends) and histories are gifts from tūpuna (ancestors) that construct a platform of knowledge, innovation and connection from which Māori can launch into the world of evaluation practice.

\section{KAUPAPA MĀORI EVALUATION}

Kaupapa Māori Evaluation is built on consensus and inter-subjective understandings and is embedded in Māori worldviews. Non-Māori evaluation often does not make world-views explicit focusing on process judgement, examination, and assessment, presenting a version or dimension of a contextual reality or truth (Patton 1990). From an Indigenous perspective, an effective model of evaluation has at its centre people, relationships, connections, and a sense of place and belonging. Kerr ( 2012) provides an excellent overview of kaupapa Māori theory, practice and scope. Data, analysis, interpretation, recommendations, and uptake all depend on collaboration and connection. A range of methods are utilised to collect data, but subtle signs and inferences provide insight into cultural value and practice. Evaluation is about listening, reflecting, and assessing whether or not a programme adds value to our collective cause and our quest for mana motuhake (Cram 2001).

Kaupapa Māori evaluation embodies decolonisation (Cram 2016). Through Kaupapa Māori evaluation, we can reclaim mātauranga Māori and empower Māori individuals and communities, including both those who are researched and those who are researchers (Edwards, McManus, and McCreanor 2005). Decolonisation is about refusing to legitimise the dominance of Western knowledge, and instead seeking power in our own philosophies, truths, and stories (Jackson 2017). Decolonising evaluation practice takes place within a space of history, presence, and future aspirations. Kaupapa Māori evaluation is part of a collective movement towards Māori autonomy which extends respectful, reciprocal and meaningful relationships with people, place, and space (Cram and Mertens 2016). Kaupapa Māori evaluation is political, and evaluators must understand that self-determination powers the aspirations of the community (LaFrance and Nichols 2010). Kaupapa Māori evaluation strives to make a positive, transformative difference in communities (Cram and Mertens 2016), serves to strengthen Māori, draws from core values, and promotes being active.

Collaboration is critical to kaupapa Māori evaluation and these collaborations are context-specific. Collaboration is based on interconnection and communality as Māori, whānau, hapū, iwi, health consumers and health workers. Collaborative approaches to health evaluation can include engaging and resourcing 
patients to become co-designers and researchers from the inception of the research through to the end. Tikanga provides a benchmark against which all relationships, recognised or potential, can be assessed and includes ways of communicating that are respectful and responsive (Mead 2003).

Māori philosophies emphasise being open to evaluation and reflection in order to assess what is tika, the right way (Henry and Pene 2001). Just as programme stakeholders and participants are located within whānau, hapū, and iwi, so too are the evaluators who evaluate the 'success' or 'failure' of these programmes. Kaupapa Māori evaluation marries the ethical and moral practice of research with the political imperative to reclaim Māori cultural practices (MastersAwatere 2015). For Māori evaluators, our role is not simply a job. The success of the evaluation depends on our ability to connect, express and reflect our perceptions, way of life and understandings of who we are as Māori (Denzin and Lincoln 2008). At each level, Māori evaluators may feel a commitment to simultaneously 'write back' against colonial authority, and to write to ourselves in support of mana motuhake (Smith 1999a). Kaupapa Māori evaluation intends to honour individual contributions that reflect diverse Māori experiences and realities, while striving towards collective advancement and Indigenous sovereignty (Cram and Mertens 2016).

\section{METHODS}

The kaupapa Māori evaluation approach used in this study aspired to co-ownership, mutually beneficial outcomes, and sharing power by prioritising patients' voices to develop the criteria for determining the effectiveness of the intervention. Ngāti Porou Hauora was involved in decision-making about methodology, interpreting and analysing data, and in the concluding stages of the evaluation. My collaborative journey through the kaupapa Māori evaluation relationships went deeper than evaluation partnership or collaboration, as I was both an insider - iwi member - and an outsider - evaluator. While my methodology is located within kaupapa Māori, it draws on and, at times aligns with elements of community-based action participatory research (Cram 2012; Stringer 2007), co-operative inquiry (Heron and Reason 1997), and co-design (Boyd et al. 2012).

Other phases of my doctoral research were attached to the aims of a wider study called the Cardiovascular Disease (CVD) Medicines Health Literacy Intervention (Lambert et al. 2014). They involved semi-structured interviews with patients, whānau and health professionals, to gain insight into their perceptions, practices, and experiences of the intervention (Crengle 2009). To complement these understandings I interviewed expert Māori and Indigenous health literacy key 
informants to add broad, professional knowledge to my developing understandings of the area. Thirty semi-structured interviews were completed with Māori patients aged from 57 to 94 years, Ngāti Porou practitioners and Indigenous health literacy key informants. Thematic analyses (Braun and Clarke 2006) present patterns in participants' narratives about their journeys through CVD. Five group meetings were held with the Ngāti Porou advisory group. Invitations to participate were an important part of the collaborative process as Ngāti Porou Hauora were involved in the methodological decisions, interpretation of data, analysis, and concluding stages of the evaluation. Our research was approved by the Massey University Ethics Committee (MUHECN 12/095), and the patient and health practitioner interview schedules were developed with feedback/approval from the Ngāti Porou Hauora research coordinator and parent project team members.

The final component of my study was built on those learnings to develop wider understandings of the health literacy interventions with Māori and other Indigenous communities. The intention was to collaboratively design this as a kaupapa Māori evaluation framework, specifically to assess the effectiveness of health literacy interventions. I worked with a Ngāti Porou Hauora research advisory group that included a pākeke (cultural advisor), a board member from the community in which the parent project was sited, a research coordinator and Ngāti Porou Hauora investigator, a manager, a chronic care nurse, a general practitioner, and a kaiāwhina (community support worker).

\section{COLLABORATIVE HUI TO DEVELOP THE FRAMEWORK}

A series of hui (meetings), were held with the advisory group to plan, outline, develop and refine the kaupapa Māori evaluation framework. Equitable collaboration and partnership were imperative to ensure that the information generated from the evaluation was context focused, and that the process honoured te reo me ōna tikanga (Māori philosophy, knowledge, practice and identity) o Ngāti Porou.

A key first step was being formally introduced to the research advisory group. I gave a short presentation about the proposed evaluation and research processes and answered questions in a discussion session. I invited them to participate collaboratively in my doctoral project and obtained agreement that they would provide advice and feedback on aspects of my work.

The second hui focused on gaining insight into the principles and aspirations that guide this specific research advisory group. I supplied a background paper, 
which presented an overview of the research and proposed kaupapa Māori methodological approach (Carlson et al. 2016). I aimed to explore both the 'principles' and 'values', and to begin developing the 'practical enactment' of these values in the form of evaluative criteria. I asked each participant to write down their goals and aspirations for the health and wellbeing of the communities they serve. I also asked them to write down the important principles that guide their practice in their respective roles. These were written on Post-it notes, placed on a whiteboard, and collaboratively grouped under themes.

Working with the goals and aspirations expressed, I sent an initial draft ${ }^{2}$ of the Ngāti Porou Hauora Health Literacy Evaluation framework to all research advisory group members for feedback. The draft also outlined data collection plans, backed by literature on current evaluation models and frameworks used in kaupapa Māori health contexts.

At the fourth hui, I presented preliminary findings from the earlier interview phase to the research advisory group and my interpretation of these core themes of relevance to the draft framework. The advisory group were asked to provide feedback on the interpretations and framework development.

The final hui included sharing developments in the framework resulting from the incorporation of key informant data and feedback, other Indigenous framework development (Hawaii i) ${ }^{3}$ and gathered final feedback from the advisory group.

\section{RESULTS}

The early stages of developing the framework focused on aspirations and values. The framework was also influenced by Durie's health promotion model, Te Pae Mahutonga (1999) and the Ngāti Porou Hauora strategic plan (2014). The research advisory group worked with me to determine Mana Motuhake o Ngāti Porou as an underpinning principle of the framework - the first level. The nonnegotiable right of mana motuhake was recognised as a commitment towards decolonising our pathway forward. We then identified the second level of goals of hauora for the community: toiora - healthy lifestyles, te oranga - participation in society, and waiora - ecological wellbeing. These goals form the second level, outlining specific goals that connect and shape hauroa. These goals were linked to key elements of Ngāti Porou tikanga: mauri ora - lived practices of te ao Māori; whakapapa - ancestral inheritance and interconnectedness; pakari - collaboration and partnership; manākitanga - equality and equity; and mātauranga - quality practices and services. These elements encompass the 
many forms of an effective and successful health literacy practice, as well as directing, and shaping the five action areas in the Ngäti Porou Hauora Health Literacy Evaluation Framework.

The consensus was that these principles, goals and elements covered core tikanga and hauora practices and the range of concepts that need to be attended to in health interventions and evaluations. These principles are interwoven expressions of what is important and necessary to health and wellbeing for Ngāti Porou. This grounded our subsequent co-design processes to identify specific criteria that would determine the effectiveness of health literacy within the Māori health organisation and more broadly within the community.

THE FRAMEWORK

The framework is presented as my conceptual synthesis of domains and action areas that relate to the principles, goals and elements of effective health literacy practice for Ngāti Porou Hauora. It is grounded in the collaborative work of the research advisory group, informed by my analysis and interpretation of interviews with patients, health professionals, and key informants. The framework is complemented with relevant literature including health literacy, patient-centred care, cultural competency, kaupapa Māori evaluation and action research literature and grounded in theory (see for example Cram 2016; Ministry of Health 2015b; Reason and Bradbury 2006; World Health Organisation 2007).

The framework reflects how each action area within domains of health systems/ services can contribute towards building health literacy and I now discuss each of these in more detail, highlighting the role of the diverse data sources on my conceptual work.

Whanaungatanga - relational practice - relates to establishing and maintaining meaningful, reciprocal, and respectful relationships. This goal focuses on shared power approaches to decision making, accountability, and resource distribution at every level of health engagement. Whānau emphasised that all approaches, services, and systems must seek to actively collaborate. For health professionals, relational practice means valuing patients as autonomous beings holding their own important and expert knowledge. This practice is developed through shared interests and consistency of care; that is, building a relationship by repeatedly seeing the same health professional. At the programme level, whanaungatanga is about streamlining approaches, preferably through kanohi kitea (to have a physical presence), so interventions align to ways of living and being. For health service providers, relational practice is about encouraging 
Table 1. Ngāti Porou Hauora Health Literacy Evaluation Framework.

\begin{tabular}{|c|c|c|c|c|c|}
\hline 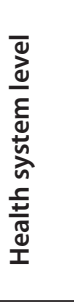 & 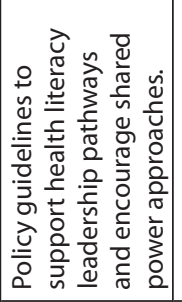 & 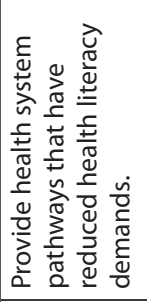 & 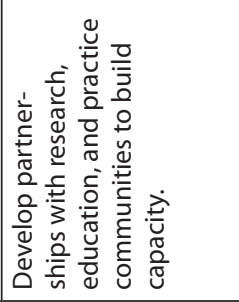 & 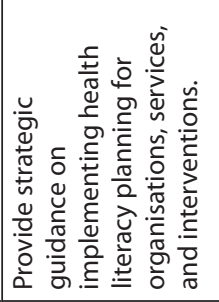 & 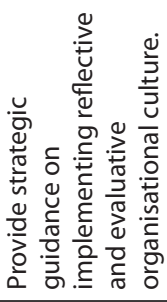 \\
\hline 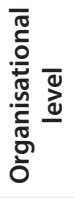 & 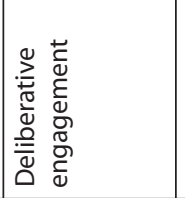 & 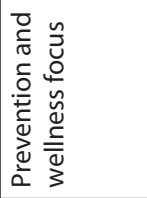 & 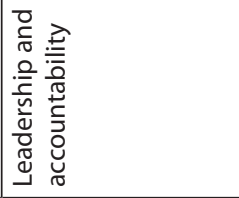 & 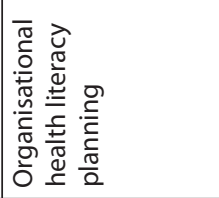 & 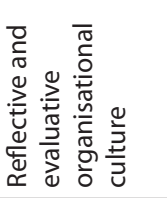 \\
\hline 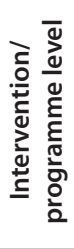 & 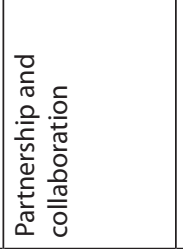 & 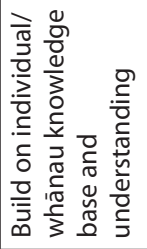 & 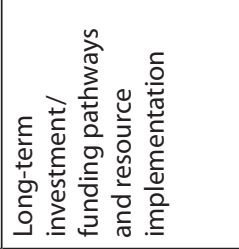 & 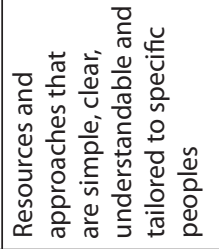 & 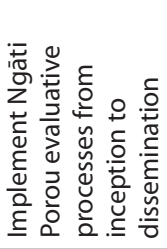 \\
\hline 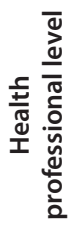 & 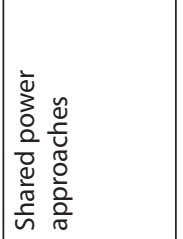 & 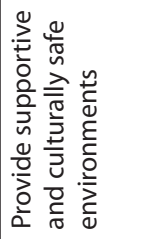 & 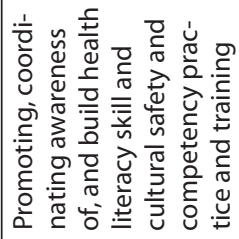 & 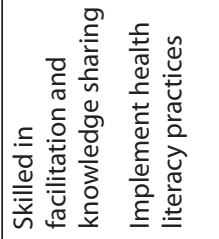 & 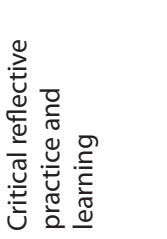 \\
\hline 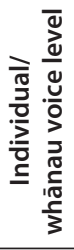 & 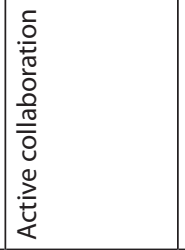 & 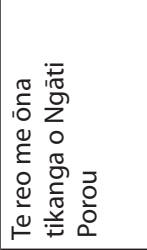 & 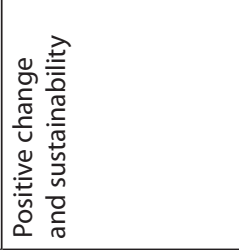 & 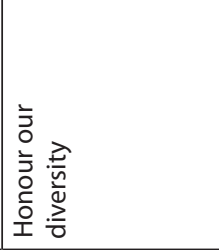 & 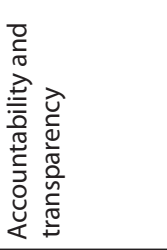 \\
\hline 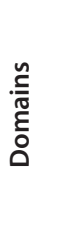 & 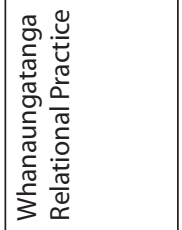 & 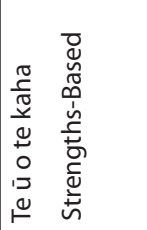 & 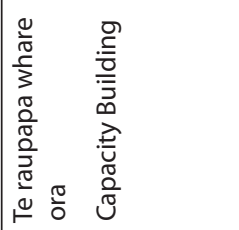 & 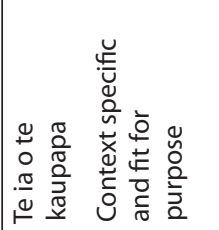 & 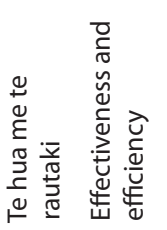 \\
\hline
\end{tabular}


and creating collaborative approaches between organisations practicing health literacy and the health workforce, including sharing resources when possible. Within the health system, this involves providing policy guidelines for organisations to develop health literacy leadership pathways and encourage shared power approaches (Ministry of Health 2015).

Te ù o te kaha - Strengths-based approaches promote prevention and wellness pathways. Creating these pathways requires holistic approaches to healthcare through understanding the interconnectedness of hinengaro (psychological), tinana (physical), wairua (spiritual), whanaungatanga (relationships), te tai ao (environment), and tātai tuarangi (cosmos). Whānau voices were concerned with the importance of offering space to lead, implement, and practice te reo me ōna tikanga o Ngāti Porou at every stage of engagement. Strengths-based health literacy practice involves health professionals, health workforce, and health service providers creating supportive environments to practice cultural protocols, native language, and intergenerational connections. Specific actions could include providing adequate consultation times, building relationships, and enabling family and extended family to be involved at the individual's request. Strengths-based programmes utilise approaches and practices that build on whānau knowledge and understanding. For health service providers, te $\overline{\mathrm{u}} \mathrm{o}$ te kaha means prioritising and investing in prevention and wellbeing pathways. To achieve this, tensions between the clinical agenda (bio medical orientated) and the patient-centred (public health/primary healthcare) need to be identified and reduced. The health system role provides strategic guidance to the health sector to support literacy activities, prevention, and wellbeing approaches - embedding literacy in policy and utilising health literacy as an asset in all health targets and approaches.

Te raupapa whare ora - Capacity building necessitates sustainable resources and practices. Whānau voiced the need for interventions to make a positive difference in our communities, strive towards practices of sustainability, and consideration of long-term impacts and outcomes on future moko-mokopuna (next generations) and their environment. Health professionals need to be skilled in facilitation and knowledge sharing. Interventions that build capacity offer patients options to develop their health literacy knowledge and skills, including invitations to review approaches and change treatment options. Te raupapa requires health professionals to participate in cultural safety and cultural competency training and practices, which should be offered, supported, and implemented by organisations. At an intervention/programme level, te raupapa highlights the need to create sustainable practices through long-term investment, from initial funding through to resource implementation and 
dissemination. Health service providers play a role in developing partnerships with research, education, and practice communities to build capacity in all approaches and action, and to maximise Māori participation in leadership roles from inception through to dissemination. The health service and system role means developing partnerships with research, education, and practice communities to build capacity in all approaches and action.

Te ia o te kaupapa - The aspiration to create context specific and fit-for-purpose interventions recognises and promotes the significance of rohenga tipuna (shared ancestors, history and location), local contexts, and diversity for all health literacy approaches. Whānau voices focused on the need to consider context in terms of rural and urban locations, access to resources and services, favoured home visit options and extended periods when working with whānau. Context-specific interventions require long-term involvement, engagement and investment in the community. Health professionals need to immediately action health literacy practices and tools. ${ }^{4}$ At the intervention/programme level, health engagements should be supported with resources that are simple, clear, and understandable. These resources should be tailored to specific audiences, and easy for patients to take home and personalise. For health services providers, te ia o te kaupapa means reviewing service and systemic practices of health literacy by examining the use of resources, signs, forms, educational material and systems to reduce health literacy barriers. Additionally, when service providers conduct health literacy planning and decision-making, or develop health resources, it is important to use high quality ethnicity data that is routinely analysed and reported. Health service providers need to act on this data, for example by spending more time and resources with populations identified as high needs or high risk. In regards to the health system, collective priorities means providing strategic guidance on implementing health literacy planning for organisations, services, and interventions to make it easier for people to utilise the system.

Te hua me te rautaki encompasses a commitment to effectiveness, efficiency, and action in all health literacy approaches. Whānau require accountable and transparent practices that ensure that all resources, outcomes, and outputs are disseminated in ways accessible to the community. For health professionals, te hua me te rautaki means continually reflecting and evaluating their practice. Striving to deliver effective and efficient health literacy means health professionals and organisations promote and coordinate action to raise awareness of and build skills in health literacy practice. When developing interventions or programmes, it is vital to implement evaluative components from inception to dissemination, improving practice along the research, intervention/ 
programme pathway. Action-based, participatory methodologies promote relationship-building practices. Organisations are responsible for supporting a culture of reflection and evaluation, and for ensuring that programmes focus on processes and outcomes, not just outputs. Again, organisations must provide training and time to undertake evaluation and reflective activities. The health system role means providing strategic guidance on implementing a reflective and evaluative organisational culture.

\section{DISCUSSION}

This research promotes the re-claiming of health literacy as a space for Māori to be ourselves, a space that is negotiated, adaptive, and shaped by people, whānau and communities (Carlson et al. 2016), and asserts the value of kaupapa Māori evaluation in addressing issues of self-determination (Cavino 2013; Cram and Mertens 2016; Kerr et al. 2010). Identifying, naming, and defining are powerful acts which can change perceptions, determine who and what has value, and drive subsequent actions, such as policy development and research (Köhler 1992). When Western terms, definitions and approaches are utilised in Indigenous communities they can reinforce colonial power processes by legitimising Western systems of ideas. Māori and the Crown have a political, legal, and spiritual covenant of equitable partnership through Te Tiriti O Waitangi (Henare 1987). This research suggests that, rather than rejecting Western terms and approaches, we can cautiously reclaim health literacy concepts and practices as our own, drawing on both mātauranga-a-iwi and Western discourse.

The Ngäti Porou Hauroa Health Literacy Evaluation Framework represents the multidimensional interrelationship of goals and actions involved in establishing effective community health literacy initiatives. The framework presented in this paper reflects participants' voices, understandings, experiences, and perceptions through adapting a Tauiwi concept/approach to support Māori health development. The co-design process for the framework reflects the practice of mana motuhake within the area of health literacy, opening up engagement between two paradigms to inform transformative and inclusive changes in our communities, our organisations, and our health system. The framework is specific to the iwi context - developed with an iwi health provider for iwi members - therefore, its strength is founded on mana motuhake o Ngāti Porou.

The framework reflects how steps can be taken towards building health literacy through whanaungatanga - establishing and maintaining meaningful, recipro$\mathrm{cal}$ and respectful relationships; te $\overline{\mathrm{u}} \mathrm{o}$ te kaha - promoting and participating in prevention and wellness pathways; te raupapa whare ora - focusing on 
sustainable resources and practices; te ia o te kaupapa - recognising the value of local context and diverse experiences, as well as prioritising high needs/risk populations; and te hua me te rautaki - commitment to action, effectiveness and efficiency.

Exploring the importance of health literacy to Māori means recognising the social and cultural environments people live within, addressing issues of power, and developing relationships that are reciprocal and responsive. Potentially, this understanding enables health professionals and evaluators to expand beyond limited functional and interactive forms of health literacy, which position Indigenous Peoples both as patients and clinicians, as less 'literate' in this domain. Interventions developed under these framings often focus on issues of individual upskilling and educational approaches rather than setting out a negotiated and shared journey. In comparison, within the Ngäti Porou Hauroa Health Literacy Evaluation Framework, mana motuhake is manifested in the engagement and collaborative and relational practices within a framework of self-determination and Indigenous control. The strength and power of this framework is in the process.

Beyond Ngāti Porou, I envisage that this framework could be adapted by other Māori health organisations for application in other research and evaluative capacities. However, I do not intend the action areas in the framework to be seen as having a linear relationship, where specific goals intersect to produce one set of actions applicable to all health literacy interventions, programmes and approaches. Rather, the framework is intended as a basis for discussion, and as a decision-making and negotiation tool for evaluation stakeholders. Evaluators using this framework must pay attention to the specific objectives of any initiative and use the framework as a reference point, rather than as a checklist to plan an intervention.

\section{CONCLUDING COMMENTS}

I began the paper with what makes us exceptional and remarkable, our Ngāti Poroutanga: our place - maunga, awa and whenua; our space - whanaungatanga, pakari, mauri ora, manaakitanga, mātauranga; and our time - lived history. I have recognised the impact of and continued effects of colonialism and our motivation in striving for action and change. I have focused on what matters to Ngāti Porou, our vision, aspirations and goals for self-determination, abundance, health and wellbeing. Finally, I have explored how reclaiming our power and decolonising health literacy enables such outcomes from a $\mathrm{Nati}^{5}$ perspective/context, for their own purposes. 
Health literacy is an approach/concept embedded in our ways of knowing and being. Kaupapa Māori evaluation is founded on mana motuhake and committed to transformative and decolonising pathways: visions of health and wellbeing for all, support for healthy lifestyles, participation in society, and ecological wellbeing. The assertion of mana motuhake in this research context means lived forms of autonomous and embodied authority (Reihana 2018), and a rejection of an assimilated future (Durie 1998). Grounded in an iwi identity, mana motuhake includes whānau-centred autonomy of wellness, health and wellbeing. Transforming health literacy means meeting people(s) on their terms. This is honoured in whanaungatanga, open and creative forms of relationship, grounded in accountability to the patients, whānau, hapū and iwi. Health literacy is inherently relational, collaborative, focused on deliberative engagement, shared power approaches and guided by te reo me ōna tikanga o Ngāti Porou, where kaupapa Māori is the theory, practice, and the framework.

Whānau see health literacy as a relational practice, a collective responsibility for all, and grounded in pathways of transparency, sustainability, accountability, and positive change. Health professionals are asked to take ownership and responsibility for their practice and individual/whānau understanding by utilising shared power approaches; promoting and coordinating health literacy practice and tools; and providing culturally safe environments. Approaches and structures are required to collaborate, build partnerships, and systematically support/provide environments for health professionals to grow, train, and lead. I have focused on the 'exo' domain of health systems/services, but I also acknowledge the importance of systemic changes that can be made at health system and societal levels to challenge cultural and social norms.

As Māori, and as peoples of Ngāti Porou, we are defining and deciding for ourselves what health and wellbeing mean. As part of this we want to reclaim the ways in which health literacy, supported by kaupapa Māori evaluation, can create pathways forward to support one another, help one another, and show love for one another.

\section{ACKNOWLEDGEMENTS}

My sincere gratitude to the kaumātua who have provided rich experiences, conversations, wisdom and continual encouragement. I would like to thank the community participants and their whānau for inviting me (Teah) into your homes, you have provided insight and grounding to the research. I would like to thank Ngāti Porou Hauora staff for your time and guidance. I also acknowledge 
the support and encouragement from the Mãori and Indigenous programme (MAI) and Whāriki Research Roopū.

This research was funded by the Health Research Council, Ngā Pae o te Māramatanga, Māori Education Trust, Massey University and the Ministry of Health.

NOTES

1 Mai i te toka-a-taiau ki te-taumata-ō-Apanui. Dr Teah Carlson is a kaupapa Māori researcher and evaluator at SHORE and Whāriki Research Centre, Massey University. She has experience in qualitative methods, strategy and evaluation, especially involving working with Māori communities where collaboration, partnership and participatory community action are key to the research development, process and outcomes. Her strengths are in kaupapa Māori research, evaluation, participatory action research, community psychology, co-design and co-creation. She has a PhD in Public Health, which was a Health Research Council-funded project entitled 'Kaupapa Māori evaluation: Transforming health literacy'

Email: t.a.carlson@massey.ac.nz

2 The third hui was held via email (telehui was offered, but email was the preferred contact method) because of resource and time constraints (related to the parent project and out of my control).

3 The Ngäti Porou Hauora Health Literacy Evaluation Framework was expanded to incorporate Indigenous health professional and community representative perspectives on goals, aspirations of health and wellbeing for the communities they serve at the 2014 World Indigenous Peoples' Conference on Education. Kapiolani Community College: O'ahu in the Hawai'i Archipelago.

4 Examples include: teach back method - checking understanding by asking patients to state in their own words what they know or do about their health; three step model-ask what people know, build health literacy skills and knowledge and check for understanding; and patient medication review - encouraging patients to bring all of their medicines and supplements to their visit and reviewing them.

5 People who descend from Ngāti Porou iwi. 


\section{REFERENCES}

Ajwani, Shilpi, Tony Blakely, Bridget Robson, Martin Tobias, and Martin Bonne. 2003. Decades of Disparity: Ethnic Mortality Trends in New Zealand 19801999. Wellington, New Zealand.

Beaglehole, John C. 1955. The Journals of Captain James Cook: The Voyage of the Endeavour 1768-1771. 1st ed. Cambridge: Cambridge University Press.

Bishop, Russell. 1999. 'Kaupapa Maori Research: An Indigenous Approach to Creating Knowledge'. In Maori and Psychology: Research and Practice, edited by Neville Robertson, 1-7. Hamilton, New Zealand: Maori and Psychology Unit.

- 2005. 'Freeing Ourselves from Neo-Colonial Domination in Research: A Maori Approach to Creating Knowledge'. In The Sage Handbook of Quality Research, edited by Norman K. Denzin and Yvonne S. Lincoln, 109-138. California: Sage Publications.

Braun, Virginia, and Victoria Clarke. 2006. 'Using Thematic Analysis in Psychology'. Qualitative Research in Psychology 3 (2):77-101.

Boyd, Hilary, Stephen McKernon, Bernie Mullin, and Andrew Old. 2012. 'Improving Healthcare through the Use of Co-Design'. The New Zealand Medical Journal 125 (1357): 76-87.

Carlson, Teah, Helen Moewaka Barnes, Susan Reid, and Tim McCreanor. 2016. 'Whanaungatanga: A Space to Be Ourselves'. Journal of Indigenous Wellbeing 1(2): 44-59.

Cavino, Hayley M. 2013. 'Across the Colonial Divide: Conversations about Evaluation in Indigenous Context'. American Journal of Evaluation 34 (3):339-55.

Cram, Fiona. 2001. 'The Validity and Integrity of Maori Research'. In Research Ethics in Aotearoa New Zealand, edited by Martin Tolich, 35-51. Auckland: Pearson Education.

- 2009. 'Maintaining Indigenous Voices'. In The Handbook of Social Research Ethics, edited by Donna Mertens and Pauline Ginsberg, 308-322. Los Angeles: Sage. 
- 2012. 'Action Research'. Katoa Ltd. http://www.katoa.net.nz/kaupapa-maori/ action-research

- 2016. 'Lessons on Decolonizing Evaluation from Kaupapa Maori Evaluation'. Canadian Journal of Program Evaluation 30 (3):296-312.

Cram, Fiona, and Te Marino Lenihan. 200o. 'Kaupapa Maori Principles, Procedures and Pratices'. Accessed 30 October 2019 from http://www.katoa.net. $\mathrm{nz} /$ past-projects/kaupapa-maori-principles

Cram, Fiona, and Donna M. Mertens. 2016. 'Negotiating Solidarlity between Indigenous and Transformative Paradigms in Evaluation'. Evaluation Matters 2:161-189.

Crengle, Sue. 2009. 'Strengthening Health Literacy Among Indigenous People Living With Cardiovascular Disease, Their Families, and Health Care Providers'. (International Collaborative Indigenous Health Research Partnership Grant). (J. Smylie, I. Anderson, M. Harwood, J. Harre Hindmarsh, S. Reid, M. Anderson, ... M. Kelaher, Eds.). Auckland: University of Auckland.

Damschroder, Laura J., David C. Aron, Rosalind E. Keith, Susan R. Kirsh, Jeffery A. Alexander, and Julie C. Lowery. 2009. 'Fostering Implementation of Health Services Research Findings into Practice: A Consolidated Framework for Advancing Implementation Science'. Implementation Science 4 (1): 50.

Denzin, Norman K., and Yvonna S. Lincoln. 2008. 'Critical Methodologies and Indigenous Inquiry'. In Handbook of Critical and Indigenous Methodologies, edited by Norman K. Denzin, Yvonna S. Lincoln, and Linda T. Smith, 1-19. Los Angeles: Sage Publications.

Durie, Mason. 1999. 'Te Pae Mahutonga: A Model for Māori Health Promotion'. Health Promotion Forum of New Zealand Newsletter 49 (2-5 December 1999).

- 2002. Te Mana, te Kāwanatanga: The Politics of Māori Self-Determination. Auckland: Oxford University Press.

- 2004. Understanding Health and Illness: Research at the Interface between Science and Indigenous Knowledge. Oxford: Oxford University Press.

- 2013. Ngā Kahui Pou: Launching Maori Futures. New York: Huia (NZ) Ltd. 
Edwards, Shane, Verne McManus, and Tim McCreanor. 2005. 'Collaborative Research with Maori on Sensitive Issues: The Application of Tikanga and Kaupapa in Research on Maori Sudden Infant Death Syndrome'. Social Policy Journal of New Zealand 25:88-204.

Hanham, Dianne. 2003. 'The Impact of Introduced Diseases in the Pre-Treaty Period 1790-1840'. Masters Thesis, University of Canterbury.

Harper, Douglas. 2012. 'Online Etymology Dictionary'. Online Etymology Dictionary. http://www.etymonline.com.

Henare, J. 1987. 'Address to David Lange’s cabinet'. Affidavit for New Zealand Māori Council v the Minister of Finance (CA. 54/187). Wellington, New Zealand.

Henry, Ella, and Hone Pene. 2001. 'Kaupapa Maori: Locating Indigenous Ontology, Epistemology and Methodology in the Academy'. Organisation: Speaking Out 8 (2): 234-242.

Heron, John, and Peter Reason. 1997. 'A Participatory Inquiry Paradigm'. Qualitative Inquiry 3 (3): 274-294.

Irwin, Kathie. 1994. 'Maori Research Methods and Processes: An Exploration'. Sites 28: 25-43.

Jackson, Moana. 2017. 'Closing Address'. Presented at He Mana Whenua Conference Indigenous Research Conference. Hamilton, University of Waikato, Te Kotahi Research Institute, 6-8 March.

Kanj, Mayagah, and Wayne Mitic. 20o9. 'Promoting Health and Development: Closing the Implementation Gap. Presented at the 7 th Global Conference on Health Promotion. Nairobi, Kenya, 26-30 October.

Karaka, H. H. 200o. Deed of settlement of historical claims. Ngati Porou Claims Settlement Bill, Supp 12, (Wai 272 affidavit of Hapukuniha Te Huakore Karaka). Ruatoria, New Zealand.

Kawakami, Alice J., Kanani Aton, Fiona Cram, Morris K. Lai, and Laurie Porima. 2007. 'Improving the Practice of Evaluation through Indigenous Values and Methods: Decolonising Evaluation Practice - Returning the Gaze from Hawai'i and Aotearoa'. Hulili: Multidiciplinary Research on Hawaiian WellBeing 4 (1):319-348. 
Kerr, Sandy. 2012. 'Kaupapa Maori Theory Based Evaluation'. Evaluation Journal of Australasia 12 (1): 6-18.

Kerr, Sandy, Liane Penney, Helen Moewaka Barnes, and Tim McCreanor. 2010. 'Kaupapa Māori Action Research to Improve Heart Disease Services in Aotearoa, New Zealand'. Ethnicity and Health 15 (1):15-31.

Köhler, Wolfgang. 1992. Gestalt Psychology: An Introduction to New Concepts in Modern Psychology. New York: Liveright.

LaFrance, Joan, and Richard Nichols. 2010. 'Reframing Evaluation: Defining an Indigenous Evaluation Framework'. Canadian Journal of Program Evaluation 23(2): 13-31.

Lambert, Michelle, Joanne Luke, Bernice Downey, Sue Crengle, Margaret Kelaher, Susan Reid, and Janet Smylie. 2014. 'Health Literacy: Health Professionals' Understandings and Their Perceptions of Barriers That Indigenous Patients Encounter'. BMC Health Services Research 14 (1): 614-24.

Lange, Raeburn. 1999. May the People Live: A History of Maori Health Development 1900-1920. Auckland: Auckland University Press.

Mahuika, A. T. 2010. 'Deed of Settlement of Historical Claims'. Ngati Porou Claims Settlement Bill, (Wai 272). Wellington, New Zealand: New Zealand Parliament.

Mancuso, Josephine M. 2009. 'Assessment and Measurement of Health Literacy: An Integrative Review of the Literature'. Nursing and Health Sciences 11 (1):77-89.

Masters-Awatere, Bridgette. 2015. “That's the Price We Pay”. Kaupapa Māori Programme Stakeholder Experiences of External Evaluation'. PhD Thesis, University of Waikato.

Mead, Hirini Moko. 2003. Tikanga Māori: Living by Māori Values. Huia Publishers. https://books.google.com/books?id=XXa3fXxLshMC\&pgis=1.

Ministry of Health. 2015. 'A Framework for Health Literacy’. Wellington.

Ngati Porou Hauora. 2014. Ngati Porou Hauora strategic plan 2014-2018. Gisborne, New Zealand: Author. Retrieved from http://www.nph.org.nz/assets/Uploads/Ngati-Porou-Hauora-Strategic-Plan.compressed.pdf 
Nicholas, J. L., and J. Watkins. 1838. British Parliamentary Papers: Colonies New Zealand. Wellington: Digital New Zealand and New Zealand Micrographic Services.

Nutbeam, Don. 2009. 'Defining and Measuring Health Literacy: What Can We Learn from Literacy Studies?' International Journal of Public Health $54(5): 303-5$.

Papen, Uta. 2006. Literacy and Globalization: Reading and Writing in Times of Social and Cultural Change. London: Routledge.

- 2009. 'Literacy, Learning and Health - A Social Practices View of Health Literacy'. Literacy and Numeracy Studies 17 (1):19-34.

Patton, Michael. 1990. Designing Qualitative Studies. Qualitative Evaluation and Research Methods. Thousand Oaks: Sage.

Peerson, Anita, and Margo Saunders. 2009. 'Health Literacy Revisited: What do we Mean and Why Does it Matter?' Health Promotion International 24(3),285296.

Pihama, Leonie, Fiona Cram, and Sheilagh Walker. 2002. 'Kaupapa Maori Principles and Practices: A Literature Review'. (A report to Te Puni Kōkiri). Wellington, New Zealand: Te Rōpū Rangahau Hauora a Eru Pōmare.

Pleasant, Andrew, Rima E. Rudd, Catina O'Leary, Michael K. Paasche-Orlow, Marin P. Allen, Wilma Alvarado-Little, and Laurie Myers. 2016. 'Considerations for a New Definition of Health Literacy'. Washington, DC: National Academy of Medicine.

Pomare, Maui. 1909. '12 April 1773'. In Historical Records of New Zealand, edited by R McNab, 2nd ed., 2o. Wellington, New Zealand: Government Printer.

Reihana, Tia L. 2018. 'Te Mana Motuhake o te Kauri: A Kaupapa Māori Exploration of Intercultural Praxis'. PhD thesis, The University of Auckland. ResearchSpace@Auckland.

Robson, Bridget, and Ricci Harris. 2007. Hauora: Maori Standards of Health IV: A Study of the Years 2000-2005. Wellington: Te Roopū Rangahau Hauora a Eru Pomare. 
Ross, Will R., Arthur Culbert, Charles Gasper, and James Kimmey. 2009. 'A Theory-Based Approach to Improving Health Literacy'. St Louis, MO: Missouri Health Foundation.

Rudd, Rima. 2012. 'Keynote address'. Health Literacy: From Discussion to Action Conference, Auckland, New Zealand, 1 May.

Rudd, Rima E., Alexa T McCray, and Don Nutbeam. 2012. 'Health Literacy and Definition of Terms'. In Health Literacy in Context: International Perspective, edited by Doris Gillis, Deborah L. Begoray, and Gillian Rowlands, 14-32. Nova Scotia: Nova Scotia Publishing.

Salmond, Anne. 1991. Two Worlds: First Meetings between Maori and Europeans, 1642-1772. Honolulu: University of Hawaii Press.

- 2017. Tears of Rangi: Experiments across Worlds. Auckland: Auckland University Press.

Social Policy Research and Evaluation Unit (Superu). 2017. Making Sense of Evaluation: A Handbook for Everyone. Wellington. https://dpmc.govt.nz/sites/ default/files/2018-03/Evaluation\%2oHandbook\%20Dec\%202017.pdf

Schulz, Peter J., and Kent Nakamoto. 2013. 'Health Literacy and Patient Empowerment in Health Communication: The Importance of Seperating Conjoined Twins'. Patient Education and Counseling 90:4-11.

Smith, Linda T. 1999a. Decolonising Methodologies. Research and Indigenous Peoples. London: Zed Books and University of Otago Press.

- 1999b. Kaupapa Maori Methodology: Our Power to Define Ourselves. A paper presented to the School of Education, University of British Columbia.

_. 2015. 'Kaupapa Māori Research - Some Kaupapa Māori Principles' In Kaupapa Rangahau: A Reader - a Collection of Readings from the Kaupapa Rangahau Workshop Series, edited by Leonie Pihama, Sarah-Jand Tiakiwai, and Kim Southey, 47-54. 2nd ed. Hamilton: University of Waikato.

Sørensen, Kristine, Stephan Van den Broucke, James Fullam, Gerardine Doyle, Jürgen Pelikan, Zofia Slonska, Helmut Brand, and Consortium Health Literacy Project European. 2012. 'Health Literacy and Public Health: A Systematic Re- 
view and Integration of Definitions and Models'. BMC Public Health 12 (80). https://doi.org/10.1186/1471-2458-12-80

Stringer, Ernest T. 2007. Action Research: A Handbook for Practitioners. Newbury Park, CA: Sage.

Tangaere, Hunaara. 1999. 'Deed of Settlement of Historical Claims'. Ngati Porou Claims Settlement Bill, Supp 12, (Wai 272 affidavit of Hunaara Tangaere). Wellington, New Zealand: New Zealand Parliament.

Walker, Shayne, Anaru Eketone, and Anita Gibbs. 2006.'An Exploration of Kaupapa Maori Research, Its Principles, Processes and Applications'. International Journal of Social Research Methodology 9 (4):331-44. 
